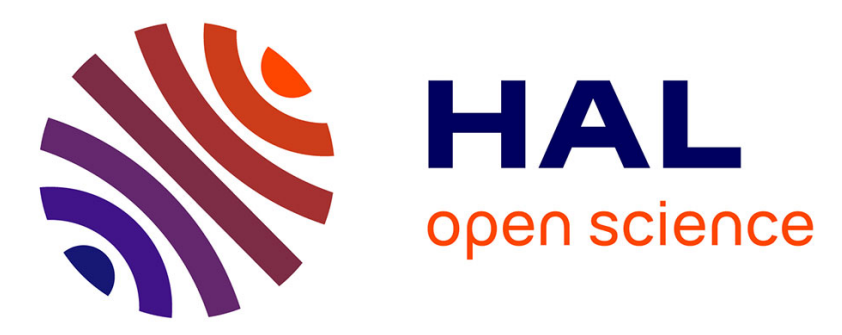

\title{
Semantic annotation for knowledge explicitation in a product lifecycle management context: a survey
}

Yongxin Liao, Mario Lezoche, Hervé Panetto, Nacer Boudjlida, Eduardo Rocha Loures

\section{- To cite this version:}

Yongxin Liao, Mario Lezoche, Hervé Panetto, Nacer Boudjlida, Eduardo Rocha Loures. Semantic annotation for knowledge explicitation in a product lifecycle management context: a survey. Computers in Industry, 2015, 71, pp.24-34. 10.1016/j.compind.2015.03.005 . hal-01123854

\section{HAL Id: hal-01123854 \\ https://hal.science/hal-01123854}

Submitted on 5 Mar 2015

HAL is a multi-disciplinary open access archive for the deposit and dissemination of scientific research documents, whether they are published or not. The documents may come from teaching and research institutions in France or abroad, or from public or private research centers.
L'archive ouverte pluridisciplinaire HAL, est destinée au dépôt et à la diffusion de documents scientifiques de niveau recherche, publiés ou non, émanant des établissements d'enseignement et de recherche français ou étrangers, des laboratoires publics ou privés. 


\title{
Semantic Annotation for Knowledge Explicitation in a Product Lifecycle Management Context: a Survey
}

\author{
Yongxin Liao $^{\mathrm{a}, \mathrm{b}, \mathrm{c}, \mathrm{i}, *}$, Mario Lezoche ${ }^{\mathrm{a}, \mathrm{b}, \mathrm{ii}}$, Hervé Panetto ${ }^{\mathrm{a}, \mathrm{b}, \mathrm{iii}}$, Nacer Boudjlida ${ }^{\mathrm{d}, \mathrm{e}, \mathrm{iv}}$ and \\ Eduardo Rocha Loures ${ }^{\mathrm{c}, \mathrm{v}}$ \\ ${ }^{a}$ Université de Lorraine, CRAN, UMR 7039, Boulevard des Aiguillettes B.P.70239, 54506 \\ Vandoeuvre-lès-Nancy, France; \\ ${ }^{b}$ CNRS, CRAN, UMR 7039, France;

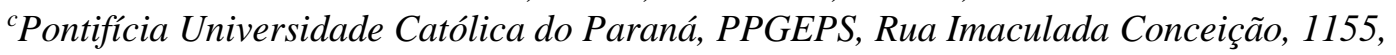 \\ Curitiba, Brazil; \\ ${ }^{d}$ Université de Lorraine, LORIA, UMR 7503, Boulevard des Aiguillettes B.P. 70239, 54506 \\ Vandoeuvre-lès-Nancy, France; \\ ${ }^{e}$ CNRS, INRIA, LORIA, UMR 7503, France
ìongxin.liao@pucpr.br, iimario.lezoche@univ-lorraine.fr, iiiiherve.panetto@univ-lorraine.fr, ivnacer.boudjlida@loria.fr, veduardo.loures@pucpr.br
*The corresponding author. His phone number is $+55413271-1101$

\begin{abstract}
Nowadays, the need for systems interoperability in or across enterprises has become more and more ubiquitous. Many research works have been carried out in the fields of information exchange, transformation, discovery and reuse. One of the main challenges in these researches is to overcome the semantic heterogeneity between enterprise applications along the life cycle of a product. As a possible solution to assist the semantic interoperability, the semantic annotation has gained many attentions and widely used in different domains. We collect a number of literature that applied semantic annotations on different objects, and classify them according to the subject being described in an enterprise architecture framework. In this paper, a detailed survey, especially from the formalization perspective, is presented to identify the existing drawbacks and to point out the possible research directions.
\end{abstract}

Keywords: Semantic Annotation; Knowledge Explicitation; Formalization; Semantic Interoperability; Product Lifecycle Management.

\section{Introduction}

In manufacturing enterprises, the Product Lifecycle Management (PLM) approach has been considered as an essential solution for improving the product competitive ability. It aims at providing a shared platform that brings together different enterprise applications 
at each stage of a Product Life Cycle (PLC) in or across enterprises [1]. Although the main software companies are making efforts to offer a complete and integrated set of systems, most of them do not provide a coherent integration of the entire information system. This results in a kind of "tower of Babel", where each application is considered as an island in the middle of the ocean of information, managed by stakeholders along the life cycle of a product.

Semantic interoperability is the ability to ensure that the exchanged information has got the same meaning considering the point of view of both the senders and the receivers [2]. In the context of a PLM, stakeholders have to work together on the exchanged information and make decisions based on it. They have different backgrounds, heterogeneous expertise, unique knowledge, particular needs and specific practices, which over increase the difficulty to achieve semantic interoperability [3]. The mutual understanding of the semantics that is embedded inside the exchanged information is the cornerstone in the quest for semantic interoperability. Being a way to realize this enrichment, the semantic explication [4] is not only just attaching the formal and shard terms between stakeholders to make semantics explicit, but also bringing the possibility to perform the semantic reasoning for some further operations.

The objective of this paper is to present a detailed survey of the collected semantic annotation literature, especially from the formalization perspective. The rest of this paper is organized as follows: Section 2 presents the definitions of annotation and semantic annotation. Section 3 illustrates and compares the semantic annotation researches being applied on different objects. Section 4 identifies the existing drawbacks and proposes the possible research directions. Section 5 concludes this paper and highlights our on-going and further research works. 


\section{Annotation and Semantic Annotation}

The Oxford dictionary defines an annotation as "a note by way of explanation or comment added to a text or diagram". It has special usages in different contexts. For example, in the software programming, an annotation is represented as a text comment embedded in codes to explain the program. In the mechanical drawing, an annotation is a snippet of text or symbol with specific meanings that illustrates the corresponding annotated part. In the commercial advertising, an annotation is usually used as a kind of footnote to detail some business restrictions.

In order to distinguish the semantic annotation from the other annotations, several kinds of classifications are proposed. Bechhofer et al. [5] categorized annotations into three types: the textual annotation, which adds notes and comments to an object; the link annotation, which extends the previous type of annotation by linking the object to an annotation content; the semantic annotation, which contains the human-readable as well as machine-readable information. Similarly, Oren et al. [6] proposed to classify annotations as: the informal annotation, which is expressed in an informal language and is not machine-readable; the formal annotation, which is machine-readable, but without any ontological terms; the ontological annotation, which is only composed of ontological terms that are commonly accepted and understood in a specific domain. These classifications identify two important features of a semantic annotation: (1) it is both human-readable and machine-readable, and (2) it contains a set of formal and shared terms that can exist for a community of human and/or machine agents.

Considering the essential of an ontology [7], which is a common agreement of a conceptualization of terms in a specific domain, different researchers have suggested many definitions of the semantic annotation related to an ontology. For example, Talantikite et al. [8] described it as "a semantic annotation is referent to an ontology". 
Lin [9] considered it as "an approach to link ontologies to the original information sources". Kiryakov et al. [10] defined it as "a specific metadata generation and usage schema, aiming to enable new information access methods and to extend the existing ones". To our knowledge, a semantic annotation can be considered as a means to perform the semantic enrichment of "something" by using a set of well formalized and commonly agreed terms from a specific domain, such as ontologies.

In our research, we mainly pay attention to two aspects of semantics that are made explicit through a semantic annotation: The domain semantics, which describes the context and the meaning of an annotated element in a specific domain; the structure semantics, which describes the interrelations between an annotated element and the other elements related to it. Taking into account these two aspects of semantics and the investigations that we have made in previous works [10][11], in the next section, we will discuss different semantic annotation methods inside the collected literature.

\section{The Investigation of Semantic Annotation Researches}

In the last decade, several surveys of semantic annotation researches have already been made with different focuses. Reeve and Han [13] presented a short survey about the classification and evaluation of six semantic annotation platforms. Uren et al. [14] reviewed and classified twenty seven semantic annotation systems according to the knowledge management requirements that they proposed. Mangold [15] presented a categorisation scheme for the classification of ten selected semantic search approaches and identified the open issues that are not addressed by those systems. Lautenbacher and Bauer [16] presented a survey to categorize and compare twenty one annotation approaches about semantic web services, grid workflows, and business process management. Hanbury [17] summarized five types of image annotation methods and then used it to analyse ten annotated image datasets. Dasiopoulou et al. [18] made a survey on 
eight image and seven video annotation tools, from both functionality and interoperability perspectives, to highlight the issues of the communication, sharing and reuse of produced metadata. Oliveira and Rocha [19] introduced and briefly compared nineteen semantic annotation tools to show the challenge in the quest to fully automatic annotation. Joksimovic et al. [20] presented an empirical study on three ontology-based semantic annotators to discover the existed issues for the future development of those examined tools.

We can find that the surveys [13], [14], [15], [19] and [20] were mainly focusing on documents, as well as the surveys [17] and [18] paid major attention to images or videos. They analysed some existing annotation tools from both the functionality perspective ([14], [15], [17], [18] and [19]) and from the efficiency perspective ([13] and [20]). A number of self-defined requirements are used as the basis to compare the semantic annotation approaches in the surveys [14] and [16]. Depict efforts have been made by above-mentioned surveys, at least two shortcomings need to be noted: (1) most of the surveys concerning the approaches that applied semantic annotations on texts, images, or videos, and few surveys have addressed models. The survey [16] is the only one that concerned the annotation on a specific kind of model (e.g. workflows). However a more recent and detailed analysis is still required; (2) among these surveys, only three of them ([13], [17] and [19]) have taken into account and generally discussed the semantic annotation methods that are embedded behind those tools. Little attention has been paid to the in-depth study and comparison of the methods, especially from the formalization perspective. This section begins with an illustration of the collected and classified semantic annotation researches (Section 3.1). Based on the literature review, we will firstly analyse and compare the semantic annotation methods inside those researches. 
Then, a more detailed discussion from the formalization perspective will be presented (Section 3.2).

\subsection{The Illustration of Semantic Annotation Researches}

With the supports of the ontologies from multiple domains and different levels, the semantic annotation approaches are widely studied and applied in diverse contexts. Concerning our research context (a PLM environment) and focus (dealing with semantic interoperability issue), the well-accepted enterprise architecture framework, named "Zachman Framework" [21], is employed as a template to assist the literature collection and classification. As it is shown in Figure 1, it presents two dimensional classification schemes for descriptive representations of an enterprise: the perspective dimension (row) and the abstraction dimension (column). For each perspective dimension in the framework, one example subject being described in the abstraction dimension is given. Based on the object of a semantic annotation research and the example subjects in the framework, the collected literature is classified into the corresponding grids. In this paper, for each annotation object, we illustrate seven collected literature as examples. Though the annotation objects of some researches might cross several subjects in the framework, in this paper, we only place them at the major subject that they worked on.

We surveyed 135 semantic annotation research works (including journal articles, conference papers, $\mathrm{PhD}$ theses and reports), fourteen of which we will illustrate and discuss in this paper. For each perspective dimension in the framework, we choose one subject as the object of the semantic enrichment. Moreover, for each chosen subject, we will present the analysis of two or three research works that applied semantic annotation on it as examples. To be more specific, this section is structured as follows: Concerning the three principal perspectives (Section 3.1.1), we illustrate the semantic annotation approaches about the "Process Models" for the Business Model Perspective (Section 
3.1.1.1), about the "Data Models" for the System Model Perspective (Section 3.1.1.2), and about the "Computer-Aided Design Models" for the Technology Model Perspective

(Section 3.1.1.3) respectively. Concerning the two additional perspectives, we take the approaches that applied sematic annotations on the "Texts" for the Scope Perspective (Section 3.1.2), and on the "Web Services" for the Detailed Representation Perspective (Section 3.1.3).

\begin{tabular}{|c|c|c|c|c|c|c|c|c|}
\hline & Data & What & Function How & \multicolumn{2}{|c|}{ Network Where } & People & Time & Motivation Why \\
\hline & \multicolumn{8}{|c|}{ 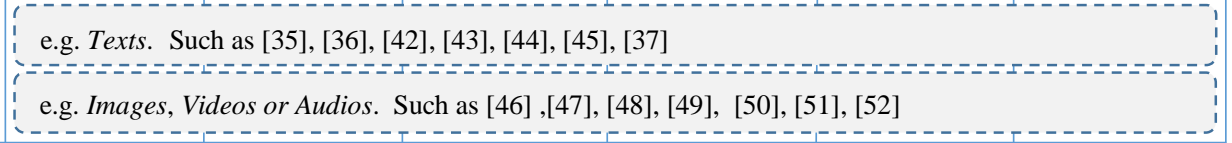 } \\
\hline $\begin{array}{l}\text { Buniness } \\
\text { Model } \\
\text { (Conceptual) }\end{array}$ & \multicolumn{3}{|c|}{ 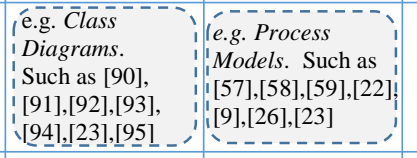 } & \multicolumn{2}{|c|}{$\begin{array}{l}\text { e.g. Business } \\
\text { Logistics System }\end{array}$} & 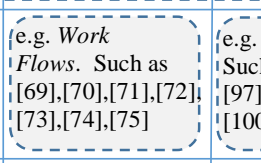 & 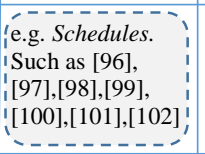 & 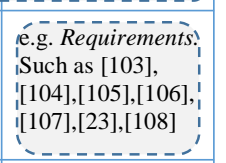 \\
\hline $\begin{array}{l}\text { System } \\
\text { Model } \\
\text { (Logical) }\end{array}$ & \multicolumn{2}{|c|}{$\begin{array}{l}\text { ie.g. Logical Data } \\
1 \text { Models. Such as } \\
1,[60],[61],[62],[30 \\
1,63],[23],[29] \\
\end{array}$} & $\begin{array}{l}\text { e.g. Application } \\
\text { Architecture }\end{array}$ & \multicolumn{2}{|c|}{$\begin{array}{l}\text { e.g. Distributed } \\
\text { System } \\
\text { Architecture }\end{array}$} & $\begin{array}{l}\text { e.g. Human } \\
\text { Interface } \\
\text { Architecture }\end{array}$ & \multirow{2}{*}{ 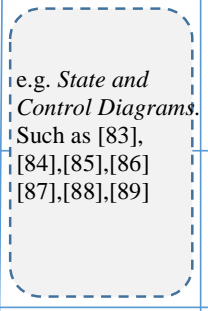 } & \\
\hline $\begin{array}{l}\text { Tec } \\
\text { Moc } \\
(P h\end{array}$ & \multicolumn{2}{|c|}{$\begin{array}{l}\text { e.g. Physical } \\
\text { Data Models }\end{array}$} & $\begin{array}{l}\text { e.g. Design } \\
\text { Models. Such as } \\
{[64],[65],[66],[32],} \\
{[67],[68],[34]}\end{array}$ & \multicolumn{2}{|c|}{$\begin{array}{l}\text { e.g. Technology } \\
\text { Architecture }\end{array}$} & $\begin{array}{l}\text { e.g. Presentation } \\
\text { Architecture }\end{array}$ & & \\
\hline $\begin{array}{l}\mathrm{D} \\
\mathrm{R} \\
(C\end{array}$ & \multicolumn{7}{|c|}{ e.g. Web Services. Such as [41], [53], [40], [54], [8], [55], [56] } & \\
\hline & \multicolumn{2}{|c|}{ e.g. Data } & e.g. Function & \multicolumn{2}{|c|}{ e.g. Network } & e.g. Organization & e.g. Schedule & e.g. Strategy \\
\hline \multicolumn{4}{|c|}{$\begin{array}{ll}\text { For Texts: } & \text { For Images, Videos or Auc } \\
\text { [35] Vargas-Vera et al. (2002) } & \text { [46] Petridis et al. (2006) } \\
\text { [36] Popov et al. (2003) } & \text { [47] Chakravarthy et al. (2) } \\
\text { [42] Cimiano et al. (2004) } & \text { [48] Saathoff et al. (2008 } \\
\text { [43] Etzioni et al. (2005) } & \text { [49] Turnbull et al. (2008) } \\
\text { [44] Buitelaar et al. (2006) } & \text { [50] Schreiber et al. (2008 } \\
\text { [45] Kiyavitskaya et al. (2009) [51] Liénou et al. (2010) } \\
\text { [37] Ma et al. (2011a) } & \text { [52] Tang et al. (2011) }\end{array}$} & os: $\begin{array}{ll}\text { Fo } \\
{[9} \\
\text { 06) } & {[9} \\
& {[9} \\
& {[9} \\
& {[9} \\
& {[9} \\
& {[9}\end{array}$ & & $\begin{array}{ll}\text { Diagrams: } & \text { F } \\
\text { di et al. (2005) } \\
\text { ardi (2005) } \\
\text { ras and Staab (2010) } \\
\text { al. (2011) } \\
\text { et al. (2012) } \\
\text { 2013) } \\
\text { ind Fillottrani (2013) }\end{array}$ & \multicolumn{2}{|c|}{$\begin{array}{l}\text { For Process Models: } \\
\text { [57] Hepp et al. (2005) } \\
\text { [58] Wetzstein et al. (2007) } \\
\text { [59] Born et al. (2007) } \\
\text { [22] Boudjlida and Panetto (2007) } \\
\text { [9] Lin(2008) } \\
\text { [26] Di Francescomarino (2011) } \\
\text { 3) [23] Liao (2013) }\end{array}$} \\
\hline \multicolumn{2}{|c|}{$\begin{array}{l}\text { For Work Flows: } \\
\text { [69] Zhao et al. (2004) } \\
\text { [70] Cantalupo et al.(2005) } \\
\text { [71] Truong et al.(2007) } \\
\text { [72] Guimarães et al. (2010) } \\
\text { [73] Missier et al.(2010) } \\
\text { [74] Oliveira et al. (2012) } \\
\text { [75] Ferreira et al.(2012) }\end{array}$} & & hedules: & $\begin{array}{l}{[106} \\
{[107} \\
{[23]} \\
{[108}\end{array}$ & & $\begin{array}{l}\text { lents: } \\
\text { and Burrell (2004) } \\
\text { al. (2005) } \\
\text { et al. (2005) } \\
\text { hl and Billig (2006) } \\
\text { 10) } \\
\text { 13) } \\
\text { et al. (2014) }\end{array}$ & \multicolumn{2}{|c|}{$\begin{array}{l}\text { For Logical Data Models: } \\
\text { 4) } 60 \text { Madnick and Zhu (2006) } \\
\text { [61] Dou et al. (2006) } \\
\text { [62] Tao and Embley (2009) } \\
\text { 6) [30] Sonia et al. (2011) } \\
\text { [63] Nogueras-Iso et al. (2012) } \\
\text { [23] Liao (2013) } \\
\text { [29] Song (2013) }\end{array}$} \\
\hline \multicolumn{3}{|c|}{$\begin{array}{l}\text { For State and Control Diagrams: } \\
\text { [83] Gašević and Devedžić (2006) } \\
\text { [84] Chen and Tu (2009) } \\
\text { [85] Seo et al. (2009) } \\
\text { [86] Park et al. (2010) } \\
\text { [87] Rahmani and Thomson (2012) } \\
\text { [88] Vidal et al. (2012) } \\
\text { [89] Choi et al. (2014) }\end{array}$} & \multicolumn{2}{|c|}{$\begin{array}{l}\text { For Rules: } \\
\text { [76] Lévy et al.(2010) } \\
\text { [77] Nazarenko et al. (2011) } \\
\text { [78] Omrane et al. (2011) } \\
\text { [79] Ma et al. (2011b) } \\
\text { [80] Sainte Marie et al. (2011) } \\
\text { [81] OMG (2013) } \\
\text { [82] Gailly and Geerts (2013) }\end{array}$} & $\begin{array}{l}{[32] \mathrm{A}} \\
{[67] \mathrm{P}} \\
{[68] \mathrm{V}} \\
{[34] \mathrm{L}}\end{array}$ & ign Models: & \multicolumn{2}{|c|}{$\begin{array}{l}\text { For Web Services: } \\
\text { [41] Patil et al. (2004) } \\
\text { [53] Agarwal et al. (2004) } \\
\text { (2009)[40] Kopecky et al. (2007) } \\
\text { [54] Martin et al. (2007) } \\
\text { [89) Talantikite et al. (2009) } \\
\text { [55] Puttonen et al. (2010) } \\
\text { [56] Cai et al. (2011) }\end{array}$} \\
\hline
\end{tabular}

Figure 1. The Classification of the Collected Literature based on the Zachman Framework 


\subsubsection{Semantic Annotations for Models}

Enterprise modelling is a process that focuses on capturing and representing knowledge from the perspectives of a system of interest. The interoperations among the systems not only require that models can be exchanged and operated on, but also demand an unambiguous understanding of the semantics inside those models.

\subsubsection{Semantic Annotations for Different Kinds of Models in an Enterprise.}

The Task Group 4 of the INTEROP project [22] investigated how annotations are able to contribute in making explicit the semantics of models in an enterprise for the purpose of enabling both semantic-based and model-based interoperability among collaborating actors. As it is shown in Figure 2, they proposed a general annotation schema for the annotation of all kinds of models. They assumed that any part within a model may be annotated and can be annotated with multiple annotations.

General Annotation Schema:

--Annotation-Id: identifier of annotation

--Unformal Content: unformal comments

--Annotation Type: Type of annotation

--Ref2Ontology: URI of ontology concept

--Constraints: refer to ontology or meta-model

Figure 2. The Semantic Annotation Schema from Boudjlida et al. (2007) [22]

Liao [23] studied the issues of the interoperability, especially the semantic interoperability problems, and proposed a formal semantic annotation method to support the mutual understanding of the semantics inside the exchanged information within a Product Lifecycle Management (PLM) context. As can be seen from Figure 3, part of the semantic annotation structure model is illustrated. It can be used to assist the construction of semantic annotation schemas for various kinds of models along the life cycle of a product and to support the design and implementation of the semantic reasoning. 
$\mathrm{SA}:=(\mathrm{E}, \mathrm{P}, \mathrm{SR}, \mathrm{MME}, \mathrm{MR})$

where

--E: a set of elements from the annotation object

--P: a set of elements from PLC-related ontologies

--MME: a set of elements from meta-model ontologies

--SR: a set of binary relations between $\mathbf{E}$ and $\mathbf{P}$

--MR: a set of binary relations between $\mathbf{E}$ and $\mathbf{M M E}$

Figure 3. The Semantic Annotation Schema from Liao (2013) [23]

\subsubsection{Semantic Annotations for Process Model}

A process model is a "linear representation of a set of variables that define a theoretically meaningful sequence of related conditions and actions" [24]. As one of the critical components in the Business Model Perspective, it is usually used as a blueprint for the design of a workflow that coordinates activities, resources, and data according to the underlying processes [25].

Di Francescomarino [26] proposed some techniques to support the annotation of business process model with ontologies, which gives the possibility to perform reasoning for assisting designers and analysts in the management of their business process models. On one hand, a semantic annotation is represented as the "textual annotations" in a business process diagram by using a “@” symbol with the name of the selected ontology class. On the other hand, an annotated element in process model has a corresponding ontology individual and is asserted to the selected class. Figure 4 shows the annotation schema that we summarized from that thesis.

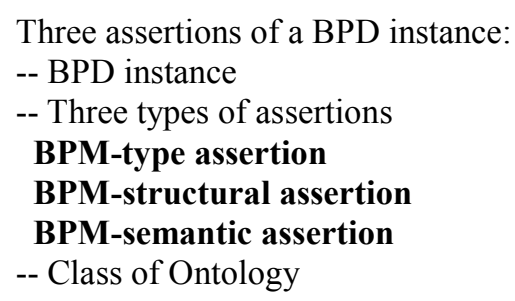

Figure 4. The Semantic Annotation Schema from Di Francescomarino (2011) [26]

Lin [9] proposed a semantic annotation framework to support the discovery and the sharing of process models in or between enterprises by reconciling the semantic 
heterogeneity between process modelling languages (meta-model) and model contents. In that thesis, the meta-model is annotated by a general process ontology (GPO) and model contents are annotated by a domain ontology. A set of refined relations is also proposed to better describe the semantic relationships between elements in models and the concepts in ontologies. As it is shown in Figure 5, a process semantic annotation model (PSAM), which describes the process properties and annotation contents, was proposed to generate a common annotation schema for different kinds of process models.

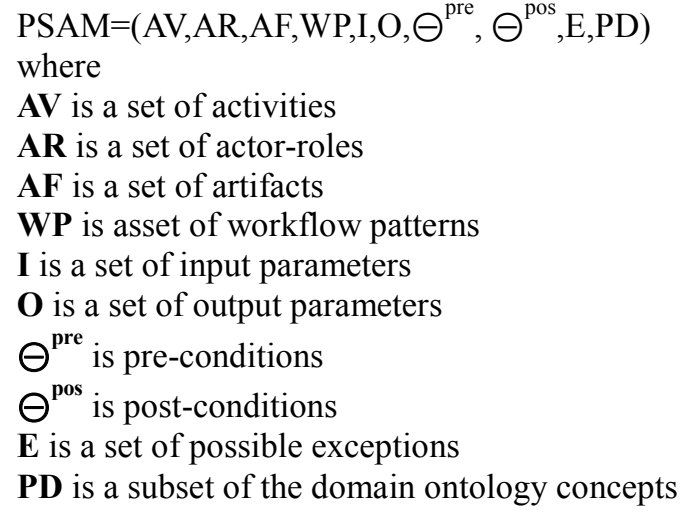

Figure 5. The Semantic Annotation Schema from Lin (2008) [9]

\subsubsection{Semantic Annotations for Data Models}

A data model is "an effective technique to define the shareable semantics that are essential to the success of data communication in an integrated environment" [27]. Although the data modelling only represents a small phase in the System Model Perspective, it probably has more impact on the final results than the other phases in a whole enterprise systems development process [28].

Song et al. [29] investigated the issues of heterogeneous data systems and proposed a semantic information layer (SIL), which acts as a mediation tool among these systems to overcome gaps of data and semantic heterogeneity. This research focused on the development of an ontology-driven framework for supporting the extraction of ontologies from different databases and assisting the creation and management of the SIL. 
Semantic annotations are automatically generated and be used as paths between the SIL and data schemas.

MOMIS project [30] proposed an annotation method to support the automatic and semi-automatic annotation on two or more data models that are extracted and converted from either structured or semi-structured data sources. Based on the annotations and the predefined semantic relationships, it generates a global schema to support the data integration between different data sources. In the annotation phase, the generic lexical database and a domain glossary are employed to provide human readable meanings for annotators. Semantic annotation is only considered as a kind of association between an element in data model and its text meanings.

\subsubsection{Semantic Annotations for Computer-Aided Design Models}

A Computer-Aided Design model can be considered as a simulated graphical representation of a product, which holds a complete depiction of information that is capable of supporting the manufacturing [31]. As one kind of models in the Technology Model Perspective, it acts as a final step of implementation or realization during the enterprise modelling phase.

Attene et al. [32] developed a semantic annotation system, named ShapeAnnotator, which is able to decompose a 3D shape into several interested features through a segmentation algorithm and to support the annotation of the selected features by connecting them to the corresponding individuals. These individuals are saved in a separated OWL [33] file with the imports of domain ontology. Figure 6 shows the annotation schema that we summarized from that research.

Annotation Schema in the ShapeAnnotator:

--Class: selected class in domain ontology

--ShannGeoContextURI: a URI refer to a multi-segmented mesh

--ShannSegmentID: an index of a segment in the multi-segmented mesh.

--Related Values: value is computed and added by the feature descriptors 
Figure 6. The Semantic Annotation Schema from Attene et al. (2009) [32]

Li [34] proposed an ontology-driven semantic annotation framework for CAD systems (OntoCAD), which provides product engineers with multiple engineering viewpoints of a product in its life cycle. In that thesis, as it is shown in Figure 7, an annotation data structure was proposed to formalize those annotations. A three layered ontology architecture knowledge base was proposed to capture, represent and manage multiple engineering viewpoint ontologies and to support the processing of querying and reasoning requests.

Annotation data structure in the OntoCAD:

-- Anchor: the geometric elements that are being represented as OWL individuals;

-- OWL properties: object property or data property in OWL;

-- Content: OWL individuals or data values.

Figure 7. The Semantic Annotation Schema from Li (2012) [34]

\subsubsection{Semantic Annotations for Texts}

In the early stage of the enterprise modelling (the Scope Perspective), the graphical or text description of information is one of the most employed descriptive methods. The semantic enrichment of texts is mainly designed to help a machine to "understand" the meaning of the annotated texts and to support automated processes, such as information navigation. Of course, not limited to this, a large number of researches have been proposed.

Vargas-Vera et al. [35] presented the MnM, an ontology-based annotation tool, which integrates web browser, ontology editor and open APIs to provide both automatic and semi-automatic supports for the annotation of texts in web pages. It is able to extract information from web pages and then fills them into a pre-defined template. Further, a simple type-based validation was proposed to verify the correctness of contents that are filled into the template. 
Popov et al. [36] developed a Knowledge and Information Management (KIM) platform, which is based on a KIM ontology and a massive knowledge base to automatic annotate, index, and retrieve documents. According to the hypothesis that Named Entities (NE), such as people and location that are referred by name, constitute the essential semantics in a document. The automatic semantic annotation is considered as the process of NE recognition and annotation. It provides for each extracted NE with two kinds of links: one link to the most specific class in KIM ontology to specify the named-entity type and the other link to the specific individual in knowledge base.

Ma et al. [37] proposed a framework to support the semantic reasoning on both domain and linguistic information that are embedded in the annotations of texts. It uses two ontologies: (1) a domain ontology to provide semantic labels (domain knowledge), and (2) a language ontology to give text model (linguistic knowledge). For the former one, as it is shown in Figure 8, a semantic annotation assertion is defined. For the latter one, it is represented as a set of OWL axioms and SWRL [38] rules, which contributes to bridge the inference constraints.

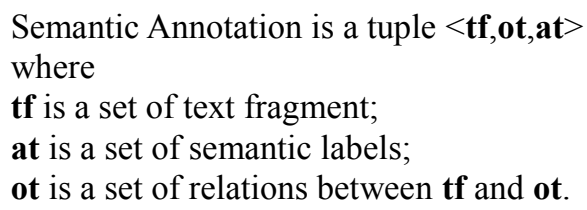

Figure 8. The Semantic Annotation Schema from Ma et al. (2011) [37]

\subsubsection{Semantic Annotations for Web Services}

A web service is "a software system designed to support interoperable machine-tomachine interaction over a network" [39]. In the Detailed Representation Perspective, adding semantic annotations to a web service is mainly for supporting the automatic verification of certain tasks, which must be executed before or during invocation of corresponding services [40]. 
Talantikite et al. [8] proposed to use semantic annotations to assist the creation of an inter-connected service network. This network is then processed by a composition algorithm and is used to discover an appropriate composition services plan for answering the corresponding user requests. As can be seen from Figure 9, they proposed a kind of annotation schema, in which the inputs and outputs are used for the similarity measurement. The exec-time and All-Resources are quality criteria for the evaluation of the best composition plan.

Semantic Annotation of Web Service (WS):

-- Sid: the identifier of a WS

-- Sname: the name of a WS

-- inputs: the input of a WS

-- outputs: the output of a WS

-- exec-time: the execution time of a WS

-- All-Resources: the required resources

-- Bindings: the used protocol

-- Service: the URI of a WS

Figure 9. The Semantic Annotation Schema from Talantikite, et al. (2009) [8]

Patil et al. [41] proposed the MWSAF, a framework for semi-automatically annotating web services with domain ontologies, to help web services discovery and composition. A semantic annotation is simply used as a "is a" association to link one element in a service and one concept in an ontology based on the linguistic similarity and structure similarity matching.

In order to simplify and standardize the complex semantic annotation methods for web services, the Semantic Annotation for WSDL and XML Schema (SAWSDL) was proposed [40]. It aims to add semantics to web services by providing extension attributes. As it is shown in Figure 10, the SAWSDL extensions can be classified into two kinds. The Model Reference (sawsdl:modelReference), which describes an association from a WSDL component or a XML Schema component to a concept in semantic models. The Schema Mapping (sawsdl:liftingSchemaMapping and sawsdl:loweringSchemaMapping), 
which specifies how an instance data in an XML Schema maps to a semantic data in a semantic model.

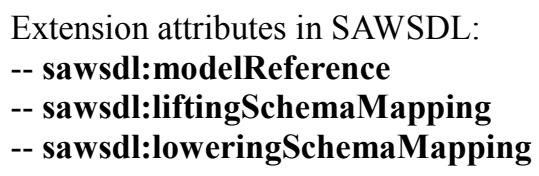

Figure 10. The Semantic Annotation Schema from Kopecký et al. (2007) [40]

\subsection{The Comparison of Semantic Annotation Researches}

\subsubsection{The Comparison: from the General Point of View}

As it is illustrated in Table 1, an overall comparison of the above-mentioned examples is presented. It firstly uses five columns to answer the questions about "What", "Why" and "How" to perform the semantic annotation. And then it uses four columns to describe the four major factors that are important for the formalization of a semantic annotation. More specifically, each column in this table is introduced as follows:

(1) The column "Application Domains" answers the question about "What to annotate?". It describes the object of semantic annotations, which relies on the context of researches (e.g. Process Models).

(2) The column "Usages of Annotation" answers the question about "Why to annotate?". We classified the reasons into the following three groups:

a) Group 1. The annotations are used to make explicit the implicit semantics of annotated elements and to improve their understandability.

b) Group 2. The annotations are used to identify the common semantics among the annotated elements that from different sources and to support similarity matching operations (e.g. transformation).

c) Group 3. The annotations are used to attach machine-readable semantics to the annotated elements and to obtain semantic reasoning supports (e.g. inference).

(3) The column "Ways of Annotation" answers part of the question about "How to 
annotate?". It describes how semantic annotations are being added to the annotated elements. The contents of this column can be "Manual", "Semiautomatic" or "Automatic".

(4) The column "Semantic Browsers" answers part of the question about "How to annotate?". It describes what browser is used to view the semantic models. In the case of automatic annotation, this column is omitted.

(5) The column "Employed Ontologies" answers part of the question about "How to annotate?". It describes what ontologies are used in the corresponding research.

(6) The column "SA verification" describes whether there is a mechanism to verify the correctness of existing semantic annotations.

(7) The column "SA Schema" describes whether there is a semantic annotation schema in the corresponding research. In this column, the simple "is a" association is not considered as a schema.

(8) The column "SA Independency" describes how semantic annotations are attached to the annotated elements. They can be embedded as references (e.g. URI) in an annotation object or stored independent from it.

(9) The column "Aspects of Semantics" describes which aspects of semantics (structure and/or domain) of an annotated element are being made explicit in the corresponding research. 
Table 1. The Comparison of Semantic Annotation Researches

\begin{tabular}{|c|c|c|c|c|c|c|c|c|c|}
\hline $\begin{array}{l}\text { Name of } \\
\text { Author(s) }\end{array}$ & $\begin{array}{l}\text { Application } \\
\text { Domains }\end{array}$ & $\begin{array}{l}\text { Usages of } \\
\text { Annotation }\end{array}$ & $\begin{array}{l}\text { Ways of } \\
\text { Annotation }\end{array}$ & $\begin{array}{l}\text { Semantic } \\
\text { Browser }\end{array}$ & $\begin{array}{l}\text { Employed } \\
\text { Ontologies }\end{array}$ & $\begin{array}{l}\text { SA } \\
\text { Verification }\end{array}$ & $\begin{array}{l}\text { SA } \\
\text { Schema }\end{array}$ & $\begin{array}{l}\text { SA } \\
\text { Independency }\end{array}$ & $\begin{array}{l}\text { Aspects of } \\
\text { Semantics }\end{array}$ \\
\hline $\begin{array}{l}\text { Boudjlida et al. } \\
(2007)[22]\end{array}$ & $\begin{array}{l}\text { Models in an } \\
\text { Enterprise }\end{array}$ & $\begin{array}{l}\text { Group 1, } \\
2 \text { and } 3\end{array}$ & Manual & $\begin{array}{l}\text { No } \\
\text { Specify }\end{array}$ & Domain & No & Yes & $\begin{array}{l}\text { Embedding } \\
\text { URIs }\end{array}$ & Both \\
\hline Liao [23] & $\begin{array}{l}\text { Models in an } \\
\text { Enterprise }\end{array}$ & $\begin{array}{l}\text { Group 1, } \\
2 \text { and } 3\end{array}$ & Manual & $\begin{array}{l}\text { Ontology } \\
\text { tree view }\end{array}$ & $\begin{array}{l}\text { Domain } \\
\text { Meta-model }\end{array}$ & Yes & Yes & Independent & Both \\
\hline $\begin{array}{l}\text { Di Francescom- } \\
\text { arino (2011) [26] }\end{array}$ & $\begin{array}{l}\text { Process } \\
\text { Models }\end{array}$ & $\begin{array}{l}\text { Group } 2 \\
\text { and } 3\end{array}$ & Semi-automatic & $\begin{array}{l}\text { No } \\
\text { Specify }\end{array}$ & $\begin{array}{l}\text { BPMN } \\
\text { and BPO }\end{array}$ & Yes & Yes & Independent & Both \\
\hline Lin (2008) [9] & $\begin{array}{l}\text { Process } \\
\text { Models }\end{array}$ & $\begin{array}{l}\text { Group 1, } \\
2 \text { and } 3\end{array}$ & Manual & $\begin{array}{l}\text { Ontology } \\
\text { tree view }\end{array}$ & $\begin{array}{l}\text { GPO, Goal and } \\
\text { Domain }\end{array}$ & No & Yes & Independent & Both \\
\hline $\begin{array}{l}\text { Song et al. } \\
\text { (2013) [29] }\end{array}$ & $\begin{array}{l}\text { Data } \\
\text { Models }\end{array}$ & $\begin{array}{l}\text { Group } 2 \\
\text { and } 3\end{array}$ & Automatic & & Domain & No & No & Independent & $\begin{array}{l}\text { Domain } \\
\text { Semantics }\end{array}$ \\
\hline $\begin{array}{l}\text { Sonia et al. } \\
\text { (2011) [30] }\end{array}$ & $\begin{array}{l}\text { Data } \\
\text { Models }\end{array}$ & $\begin{array}{l}\text { Group 1, } \\
2 \text { and } 3\end{array}$ & $\begin{array}{l}\text { Manual, Semi- } \\
\text { and Automatic }\end{array}$ & $\begin{array}{l}\text { Natural } \\
\text { Language }\end{array}$ & $\begin{array}{l}\text { WordNet and } \\
\text { Domain Glossary }\end{array}$ & No & No & $\begin{array}{l}\text { No } \\
\text { Specify }\end{array}$ & $\begin{array}{l}\text { Domain } \\
\text { Semantics }\end{array}$ \\
\hline $\begin{array}{l}\text { Attene et al. } \\
\text { (2009) [32] }\end{array}$ & CAD Models & Group 3 & Manual & $\begin{array}{l}\text { Ontology } \\
\text { graph view }\end{array}$ & Domain & No & Yes & Independent & Both \\
\hline Li (2012) [34] & CAD Models & $\begin{array}{l}\text { Group 1, } \\
2 \text { and } 3\end{array}$ & Manual & $\begin{array}{l}\text { Ontology } \\
\text { tree view }\end{array}$ & STEP & No & Yes & Independent & $\begin{array}{l}\text { Domain } \\
\text { Semantics }\end{array}$ \\
\hline $\begin{array}{l}\text { Vargas-Vera et } \\
\text { al. (2002) [35] }\end{array}$ & Texts & $\begin{array}{l}\text { Group } 1 \\
\text { and } 3\end{array}$ & $\begin{array}{l}\text { Manual, Semi- } \\
\text { and Automatic }\end{array}$ & $\begin{array}{l}\text { Ontology } \\
\text { tree view }\end{array}$ & Domain & No & No & $\begin{array}{l}\text { Embedding } \\
\text { tags }\end{array}$ & $\begin{array}{l}\text { Domain } \\
\text { Semantics }\end{array}$ \\
\hline $\begin{array}{l}\text { Popov et al. } \\
(2003) \text { [36] }\end{array}$ & Texts & $\begin{array}{l}\text { Group } 1 \\
\text { and } 3\end{array}$ & Automatic & & $\begin{array}{l}\text { KIM } \\
\text { Knowledge base }\end{array}$ & No & No & $\begin{array}{l}\text { Embedding } \\
\text { URIs }\end{array}$ & $\begin{array}{l}\text { Domain } \\
\text { Semantics }\end{array}$ \\
\hline $\begin{array}{l}\text { Ma et al. } \\
\text { (2011) [37] }\end{array}$ & Texts & $\begin{array}{l}\text { Group } 2 \\
\text { and } 3\end{array}$ & Automatic & & $\begin{array}{l}\text { Domain } \\
\text { Language }\end{array}$ & Yes & Yes & Independent & Both \\
\hline $\begin{array}{l}\text { Talantikite, et } \\
\text { al. (2009) [8] }\end{array}$ & $\begin{array}{l}\text { Web } \\
\text { Services }\end{array}$ & Group 3 & No mention & $\begin{array}{l}\text { No } \\
\text { Specify }\end{array}$ & Domain & No & Yes & Independent & $\begin{array}{l}\text { Domain } \\
\text { Semantics }\end{array}$ \\
\hline $\begin{array}{l}\text { Patil et al. } \\
(2004)[41]\end{array}$ & $\begin{array}{l}\text { Web } \\
\text { Services }\end{array}$ & Group 3 & $\begin{array}{l}\text { Manual and } \\
\text { Semi-automatic }\end{array}$ & $\begin{array}{l}\text { Ontology } \\
\text { tree view }\end{array}$ & Domain & No & No & $\begin{array}{l}\text { Embedding } \\
\text { concepts }\end{array}$ & $\begin{array}{l}\text { Domain } \\
\text { Semantics }\end{array}$ \\
\hline $\begin{array}{l}\text { Kopecký et al. } \\
\text { (2007) [40] }\end{array}$ & $\begin{array}{l}\text { Web } \\
\text { Services }\end{array}$ & $\begin{array}{l}\text { No } \\
\text { Specify }\end{array}$ & $\begin{array}{l}\text { No } \\
\text { Specify }\end{array}$ & $\begin{array}{l}\text { No } \\
\text { Specify }\end{array}$ & $\begin{array}{l}\text { No } \\
\text { Specify }\end{array}$ & $\begin{array}{l}\text { No } \\
\text { Specify }\end{array}$ & Yes & $\begin{array}{l}\text { Embedding } \\
\text { URIs }\end{array}$ & $\begin{array}{l}\text { No } \\
\text { Specify }\end{array}$ \\
\hline
\end{tabular}


This comparison emphasizes several key information in a semantic annotation research, including: (1) Most of the semantic annotation researches focused on using semantic annotations to support the usage Group 3. (2) In the cases of manual and semiautomatic annotation, most of the researches provided ontology tree view as the semantic browser. (3) The verification mechanism is not taken into account by most of the semantic annotation researches. (4) Various kinds of semantic annotation schemas have been proposed by different researches. (5) In the case of semantic annotation for Web Services and Texts, semantic annotations are always embedded inside the annotation objects. To the contrary, concerning Models, semantic annotations are always independent. (6) Less than half of the researches take into account the structure semantics.

Furthermore, we discovered that there exists two extremes of the semantic annotation researches: (1) The researches that focus on developing an appropriate knowledge base, which has high-coverage of semantics, for example, the researches [35] and [36]. (2) The researches that focus on discovering a suitable semantic annotation structure model and related mechanisms, which has high-adaptability to different knowledge bases, for example, the researches [22], [23] and [40]. The challenges for the first direction are mainly the completeness and multiplicity of semantic models. The challenges for the second direction are mainly the applicability and tolerance of annotation models and related mechanisms. According to our research interest (the analysis of semantic annotation methods), in the next section, we will present a more detailed comparison from the formalization perspective.

\subsubsection{The Comparison: from the Formalization Perspective}

Totally, night semantic annotation schemas are discovered from the compared researches (Table 1). As it is shown in Figure 11, the elements inside those schemas are categorized into six types as follows: 
(1) Element type (1), which contains the identifier of the annotated element.

(2) Element type (2), which contains the domain semantics.

(3) Element type (3), which contains the structure semantics.

(4) Element type (4), which contains the relations between the annotated element (that identified by (1)) and its domain or structure semantics (2) or (3)).

(5) Element type 5), which contains some specific properties that are associated to the annotated element. It does not describe the semantics of the annotated element.

(6) Element type 6, which contains some specific properties that are associated to the semantic annotation itself. 
General Annotation Schema:

--Annotation-Id: identifier of annotation $---\rightarrow$ (6)

--Unformal Content: unformal comments --- 5

--Annotation Type: Type of annotation $\quad--\rightarrow$ (6)

--Ref2Ontology: URI of ontology concept $--\rightarrow$ (2)

--Constraints: refer to ontology or meta-model $\rightarrow$ (3)

(a)

$\mathrm{SA}:=(\mathrm{E}, \mathrm{P}, \mathrm{SR}, \mathrm{MME}, \mathrm{MR})$

where

E: a set of elements from the annotation object $--\rightarrow$ (1) Annotation structure in OntoCAD:

P: a set of elements from PLC-related ontologies- $\rightarrow$ (2)--Anchor: the geometric elements that are

MME: a set of elements from meta-model ontologies

SR: a set of binary relations from $\mathbf{E}$ to $\mathbf{P}-------\rightarrow(4)$

MR: a set of binary relations from $\mathbf{E}$ to $\mathbf{M M E}---\rightarrow(4)$

(b)

Three assertions of a BPD instance:

-- BPD instance ----------------- 1

-- Three types of assertions -------- $\rightarrow$ (4)

BPM-type assertions

BPM-structural assertions

BPM-semantic assertions

-- Class of Ontology

(c)

PSAM $=\left(A V, A R, A F, W P, I, O, \ominus^{\text {pre }}, \Theta^{\text {pos }}, E, P D\right)$

where

$\mathbf{A V}$ is a set of activities ------------------- 1 (1)

$\mathbf{A R}$ is a set of actor-roles --------------- $\rightarrow$

AF is a set of artifacts ----------------- $>$ (1)

WP is asset of workflow patterns -------- 1

I is a set of input parameters ------------ 1 (1)

$\mathbf{O}$ is a set of output parameters----------- $\rightarrow$

$\Theta^{\text {pre }}$ is a set of pre-conditions ----------- $\rightarrow$

$\Theta^{\text {pos }}$ is a set of post-conditions --------- $\rightarrow$ (1)

$\mathbf{E}$ is a set of possible exceptions --------- $\rightarrow$

PD is a subset of the domain ontology concepts $\rightarrow$ (2)

(d)
Annotation Schema in the shapeAnnotator:

--Class: selected class in domain ontology---> (2)

--ShannGeoContextURI: a URI refer to a

multi-segmented mesh ---------------------- (5)

--ShannSegmentID: an index of a segment

in the multi-segmented mesh. -------------> (1)

--Related Values: value is computed and added by the feature descriptors

(e) being represented as OWL individuals;-- $\rightarrow$ (1) --OWL properties: object property or data property in OWL; ----------------> (4)

-Content: OWL individuals or data values $\rightarrow>$ (2)

(f)

Semantic Annotation is a tuple $<\mathbf{t f}, \mathbf{o t}$,at $>$ where

tf is a set of text fragment; ---------------- (1)

at is a set of semantic labels; -------------- 2

ot is a set of relations between $\mathbf{t f}$ and ot.---> (4)

(g)

Semantic Annotation of Web Service (WS):

-- Sid: the identifier of a WS ------------- 1

-- Sname: the name of a WS -------------- 5

-- inputs: the input of a WS --------------> (2) (5)

-- outputs: the output of a WS -------------> (2) (5)

-- exec-time: the execution time of a WS--- $\rightarrow$ (5)

-- All-Resources: the required resources $---\rightarrow 5$

-- Bindings: the used protocol ------------- 5

-- Service: the URI of a WS ----------> 5

(h)

Extension attributes in SAWSDL:

-- sawsdl:modelReference ---------------> (2)

-- sawsdl:liftingSchemaMapping---------- $\rightarrow$

-- sawsdl:loweringSchemaMapping ------ (5)

(i)

Figure 11. The Comparison of Semantic Annotation Schemas

Combining the element type (1) with the column "SA independency" in Table 1, we can discover that this type of elements only exist in (b), (c), (d), (e), (f), (g) and (h). They belong to the researches that store semantic annotation independently. To the contrary, for those researches which embed references in the annotation objects, their schemas, such as (a) and (i), do not contain this type of elements. 
All the schemas contain element type (2). Besides (a) and (i) which express this type of elements as URIs, the rest of them use ontology concepts. It is normally used to make explicit the domain semantics of the annotated elements. However, in (h), it is used to express the domain semantics of the annotated elements' inputs and outputs.

Based on the observation of those schemas, only (a), (b) and (c) contain the element type (3). However, after analysis, we discover that the structure semantics are also taken into account by (d), (e) and (g). In (d), besides element $P D$, the rest of the elements in the schema are generated based on a meta-model ontology, named GPO. After mapping a meta-model to GPO, the corresponding model element is converted as an individual of the mapped class in GPO. In (e) and (g), structure semantics are not directly presented in the schema. Instead, the former one expressed it through the topological relations between two features (e.g. adjacency). The latter one represented it as a text model (language ontology) with pre-defined axioms.

Outwardly, besides (b), (c), (f) and (g), the rest of the schemas do not contain the element type (4), which defines the semantic relationship as a simple assertion or a link between an annotated element and its domain or structure semantics. In (b), there are two types of relations. The $S R$ is a set of binary relations that describes the semantic relationships from the $E$ to the $P$. The MR is a set of binary relations, which describes the semantic relationships from the $E$ to the $M M E$. In (c), relations are represented as three types of assertions. The "BPM-type assertions" assert an instance to a class of the BPMN ontology. The "BPM-semantic assertions" assert an instance to a class of a domain otology. The "BPMstructure assertion" is used to describe the relations between two instances. In (f), the definitions of the "owl:ObjectProperty" and the "owl:DatatypeProperty" from OWL are 
refined. The former one denotes the annotation content is an individual and the latter one denotes the annotation content is a data value. In $(\mathrm{g})$, relations are classified into four kinds. The "sa:Concept" states the tf (text fragment) is annotated by an class. The "sa:Role" states the $t f$ is annotated by a property. The "sa:Individual" states the tf is annotated by an individual. The "sa:Ind-Con" states the $t f$ is an individual, as well as the annotation content

is the class that the $t f$ belongs to. Although element type (4) does not directly appear in (d), the semantic relationships are represented as OWL properties, such as Synonym, Polysemy, Hypernym, Hyponym, Meronym, Holonym, and Instance.

Element type (5) and (6) are usually used as a kind of additional elements of a semantic annotation to fulfil some particular requirements. For example, in (h), the "exec-time" is a property of the annotated element, which is used to record the execution time of a web service request. In (g) "Annotation-Id" is a property that is associated to the annotation itself, which is used to record the value of the identifier of that annotation.

\section{Existing Drawbacks and Possible Research Directions}

As discussed in previous sections, we found that despite lots of efforts have been made in semantic annotation researches, at least, three existing drawbacks can be noted.

The formalization of semantic annotations is not the focus in some of abovementioned researches ([29], [30], [35], [36] and [41]), where it is only considered as a kind of "is a" association between an annotated element and an ontology concept. Meanwhile, some specific schemas are proposed by some of the rest ([8], [9], [26], [32], [34] and [37]). However, these schemas are difficult to be reused in other researches but the studied ones. There exists a kind of general schemas in the research [22], [23] and [40]. The research [22] 
presented a general annotation schema, which still needs to be further formalized in more details. The research [23] acted as a successor of the previous research, and detailed the semantic annotation through a number of formal definitions. The research [40], although it provides to its user a large degree of freedom, it does not contain any semantic relationships and additional conventions.

Making explicit the domain semantics is the only concern in some of abovementioned researches ([8], [29], [30], [34], [35], [36] and [41]), where the structure semantics is ignored. The advantages of making explicit the structure semantics have been acquired by the rest of them ([9], [22], [23], [26], [32] and [37]). In the research [9], it is used as a mediator for the reconciliation of various process modelling language constructs. In the research [22], it is used to express modelling construct and support models transformations. In the research [26], it is used to support the verification of modelling constraints. In the research [32], it is used to support the automatic computation of relations between features in a model. In the research [37], it is used to support the creation of text model and conserve linguistic knowledge. Among above-mentioned usages, the structure semantics and domain semantics are used separately. The research [23] is the only one that proposed to combine both aspects of semantics in the reasoning phase. However, this proposition needs the hypothesis that the interconnections between domain and meta-model ontologies are already prepared.

In the cases of automatic or semi-automatic annotation, semantic annotations are usually suggested by some similarity measurements methods ([26], [29], [30] and [41]) or training corpus([35], [36] and [37]). The correctness verification of semantic annotations is only taken into account by the researches [26] and [37]. In the research [26], four axioms were proposed to prevent erroneous annotations according to the types of concepts. In the research [37], two SWRL rules were designed to report missing and erroneous annotations 
on a noun compound. However, these two researches only focus on the verification of one annotation on an annotated element. In the case of manual annotation, the research [23] designed three mechanisms to detect conflicts between two semantic annotations and to identify possible mistakes in an annotated model. Nonetheless, the proposed mechanisms relied on the hypothesis that the semantic similarity between two objects can be measured.

Therefore, taking into account all above considerations, three possible research directions for a future semantic annotation research are identified as follows:

(1) The novel application of semantic annotations. According to the classification of collected semantic annotation literature, as it is shown in Figure 1, more research efforts are needed to apply the semantic annotations on the subjects being described in the empty grids.

(2) The standardization of the semantic annotation process. The standardization of the essential procedures to apply the semantic annotation, which can be easily adopted by other semantic annotation researches. For the semantic annotation structure model, it is supposed to contain, at least, the element type (1), (2) and/or (3), and (4).

(3) The maintaining of annotation consistency. Along with the versioning of annotated objects and the evolution of ontologies, there remains a promising challenge to carry out future researches in maintaining the consistency of semantic annotations.

\section{Conclusion}

In a PLM environment, various kinds of representations are used to capture and describe the knowledge related to a product along its life cycle. During the collaboration, a mutual understanding of the semantics inside these shared and exchanged knowledge representations 
is the foundation to achieve the semantic interoperability. In this paper, we present a survey on a number of collected semantic annotation literature and provide a detailed comparison and discussion, especially from the formalization perspective. Based on this survey, several existing drawbacks and possible research directions are identified. In our on-going and future research works, we intend to enrich this survey with a more complete analysis from different perspectives, such as implementation and performance perspectives.

\section{Acknowledgement}

The authors would like to thank the financial support provided by the Charles Hermite Research Federation (CNRS FR 3198), the "Région Lorraine" local government, and the Pontifícia Universidade Católica do Paraná (PUCPR).

\section{References}

[1] F. Ameri and D. Dutta, "Product Lifecycle Management: Closing the Knowledge Loops," Comput. Aided. Des. Appl., vol. 2, pp. 577-590, 2005.

[2] S. Pokraev, D. Quartel, M. W. A. Steen, and M. Reichert, "Semantic Service Modeling: Enabling System Interoperability," in Enterprise Interoperability - New Challenges and Approaches, G. Doumeingts, J. Müller, G. Morel, and B. Vallespir, Eds. London: Springer London, 2007, pp. 221-230.

[3] A. Etienne, E. Guyot, D. Van Wijk, and L. Roucoules, "Specifications and Development of Interoperability Solution Dedicated to Multiple Expertise Collaboration in a Design Framework.," Int. J. Prod. Lifecycle Manag., vol. 5, no. 2, pp. 272-294, 2011.

[4] M. Zdravković, H. Panetto, M. Trajanović, and A. Aubry, "Explication and semantic querying of enterprise information systems," Knowl. Inf. Syst., vol. 40, no. 3, Apr. 2013.

[5] S. Bechhofer, L. Carr, C. Goble, S. Kampa, and T. Miles-Board, "The Semantics of Semantic Annotation," in Proceedings of the 1st International Conference on Ontologies, Databases and Applications of SEmantics (ODBASE), Irvine, California, 2002, vol. 2519, pp. 1152-1167.

[6] E. Oren, K. H. Möller, S. Scerri, S. Handschuh, and M. Sintek, "What Are Semantic Annotations," Technical Report, Galway, Ireland, 2006.

[7] T. R. Gruber, "A translation approach to portable ontology specifications," Knowl. Acquis., vol. 5, no. 2, pp. 199-220, Jun. 1993. 
[8] H. N. Talantikite, D. Aissani, and N. Boudjlida, "Semantic annotations for web services discovery and composition," Comput. Stand. Interfaces, vol. 31, no. 6, pp. 1108-1117, Nov. 2009.

[9] Y. Lin, "Semantic Annotation for Process Models: Facilitating Process Knowledge Man-agement via Semantic Interoperability," PhD Thesis, Norwegian University of Science and Technology, 2008.

[10] A. Kiryakov, B. Popov, I. Terziev, D. Manov, and D. Ognyanoff, "Semantic annotation, indexing, and retrieval," Web Semantics: Science, Services and Agents on the World Wide Web, vol. 2. pp. 49-79, 2004.

[11] Y. Liao, M. Lezoche, H. Panetto, and N. Boudjlida, "Why, Where and How to Use Semantic Annotation for Systems Interoperability," in Proceedings of the 1st UNITE Doctoral Symposium, Bucharest, Romania, 2011, pp. 71-78.

[12] Y. Liao, M. Lezoche, H. Panetto, and N. Boudjlida, "Semantic Annotation Model Definition for Systems Interoperability," in Proceedings of the 6th International Workshop on Enterprise Integration, Interoperability and Networking (EI2N), Hersonissos, Crete, Greece, 2011, pp. 61-70.

[13] L. Reeve and H. Han, "Survey of semantic annotation platforms," in Proceedings of the 20th Annual ACM Symposium on Applied Computing, Santa Fe, New Mexico, USA, 2005, pp. 1634-1638.

[14] V. Uren, P. Cimiano, J. Iria, S. Handschuh, M. Vargas-Vera, E. Motta, and F. Ciravegna, "Semantic annotation for knowledge management: Requirements and a survey of the state of the art," Web Semant. Sci. Serv. Agents World Wide Web, vol. 4, no. 1, pp. 14-28, 2006.

[15] C. Mangold, "A survey and classification of semantic search approaches," Int. J. Metadata, Semant. Ontol., vol. 2, no. 1, pp. 23-34, 2007.

[16] F. Lautenbacher and B. Bauer, "A Survey on Workflow Annotation \& Composition Approaches," in Proceedings of the Workshop on Semantic Business Process and Product Lifecycle Management (SemBPM) in the context of the European Semantic Web Conference (ESWC), Innsbruck, Austria, 2007, pp. 12-23.

[17] A. Hanbury, "A survey of methods for image annotation," J. Vis. Lang. Comput., vol. 19, pp. 617-627, 2008.

[18] S. Dasiopoulou, E. Giannakidou, G. Litos, P. Malasioti, and Y. Kompatsiaris, "A survey of semantic image and video annotation tools," in Knowledge-Driven Multimedia Information Extraction and Ontology Evolution, G. Paliouras, C. D. Spyropoulos, and G. Tsatsaronis, Eds. Springer Berlin Heidelberg, 2011, pp. 196-239.

[19] P. Oliveira and J. Rocha, "Semantic annotation tools survey," in the 2013 IEEE Symposium on Computational Intelligence and Data Mining (CIDM), 2013, pp. 301307.

[20] S. Joksimovic, J. Jovanovic, D. Gasevic, A. Zouaq, and Z. Jeremic, "An empirical evaluation of ontology-based semantic annotators," in Proceedings of the 7th international conference on Knowledge Capture (K-CAP), Banff, Canada, 2013, pp. 109-112.

[21] J. A. Zachman, "The Zachman Framework For Enterprise Architecture: Primer for Enterprise En-gineering and Manufacturing," 2002.

[22] N. Boudjlida and H. Panetto, "Enterprise semantic modelling for interoperability," in 2007 IEEE Conference on Emerging Technologies \& Factory Automation (EFTA '07), Patras, Greec, 2007, pp. 847-854. 
[23] Y. Liao, "Semantic Annotations for Systems Interoperability in a PLM Environment," PhD Thesis University of Lorraine, 2013.

[24] D. Vredenburgh and Y. Brender, "The Hierarchical Abuse of Power in Work Organizations," J. Bus. Ethics, vol. 17, no. 12, pp. 1337-1347, 1998.

[25] M. Zur Muehlen, "Organizational Management in Workflow Applications - Issues and Perspectives," Inf. Technol. Manag., vol. 5, no. 3-4, pp. 271-291, 2004.

[26] C. Di Francescomarino, "Semantic Annotation of Business Process Models," PhD Thesis, University of Trento, 2011.

[27] S. C. Feng, "A dimension and tolerance data model for concurrent design and systems integration,” J. Manuf. Syst., vol. 14, no. 6, pp. 406-426, Jan. 1995.

[28] D. L. Moody and G. G. G. Shanks, "What Makes a Good Data Model? Evaluating the Quality of Entity Relationship Models," in Proceedings of the13th International Conference on the Entity-Relationship Approach Manchester, United Kingdom, 1994, pp. 94-111.

[29] F. Song, "Contribution of ontology alignment to enterprise interoperability," $\mathrm{PhD}$ Thesis, University of Bordeaux 1, 2013.

[30] S. Bergamaschi, D. Beneventano, A. Corni, E. Kazazi, M. Orsini, L. Po, and S. Sorrentino, "The Open Source release of the MOMIS Data Integration System," in Proceedings of the 19th Italian Symposium on Advanced Database Systems (SEBD), Maratea, Italy, 2011, pp. 175-186.

[31] N. Bugtai and R. I. M. Young, "Information models in an integrated fixture decision support tool," J. Mater. Process. Technol., vol. 76, no. 1-3, pp. 29-35, Apr. 1998.

[32] M. Attene, F. Robbiano, M. Spagnuolo, and B. Falcidieno, "Characterization of 3D shape parts for semantic annotation," CAD Comput. Aided Des., vol. 41, no. 10, pp. 756-763, 2009.

[33] W3C, “OWL 2 Web Ontology Language," 2012. [Online]. Available: http://www.w3.org/TR/owl2-overview/.

[34] C. Li, "Ontology-Driven Semantic Annotations for Multiple Engineering Viewpoints in Computer Aided Design," PhD Thesis, University of Bath, 2012.

[35] M. Vargas-Vera, E. Motta, J. Domingue, M. Lanzoni, A. Stutt, and F. Ciravegna, "MnM: Ontology Driven Semi-automatic and Automatic Support for Semantic Markup," in Proceedings of the 13th International Conference on Knowledge Engineering and Knowledge Management. Ontologies and the Semantic Web, Sigüenza, Spain, 2002, vol. 2473, pp. 379-391.

[36] B. Popov, A. Kiryakov, A. Kirilov, D. Manov, D. Ognyanoff, and M. Goranov, "KIM - Semantic Annotation Platform," in Proceedings of the 2nd International Semantic Web Conference, Sanibel Island, FL, USA, 2003, vol. 2870, pp. 834-849.

[37] Y. Ma, F. Lévy, and S. Ghimire, "Reasoning with Annotations of Texts," in Proceedings of the 24th International Florida Artificial Intelligence Research Society Conference, Palm Beach, Florida, USA, 2011, pp. 192-197.

[38] W3C, "SWRL: A Semantic Web Rule Language Combining OWL and RuleML," 2004. [Online]. Available: http://www.w3.org/Submission/SWRL/.

[39] H. Haas and A. Brown, "Web Services Glossary," W3C Working Group Note (11 February 2004), 2004. [Online]. Available: http://www.w3.org/TR/ws-gloss/.

[40] J. Kopecký, T. Vitvar, C. Bournez, and J. Farrell, "SAWSDL: Semantic Annotations for WSDL and XML Schema," IEEE Internet Comput., vol. 11, no. 6, pp. 60-67, Nov. 2007. 
[41] A. Patil, S. Oundhakar, A. Sheth, and K. Verma, "Meteor-s web service annotation framework," in Proceedings of the 13th International Conference on World Wide Web, 2004, pp. 553-562.

[42] P. Cimiano, S. Handschuh, and S. Staab, "Towards the self-annotating web," in Proceedings of the 13th conference on World Wide Web, New York, USA, 2004, pp. 462-471.

[43] O. Etzioni, M. Cafarella, D. Downey, A.-M. Popescu, T. Shaked, S. Soderland, D. S. Weld, and A. Yates, "Unsupervised named-entity extraction from the Web: An experimental study," Artif. Intell., vol. 165, no. 1, pp. 91-134, Jun. 2005.

[44] P. Buitelaar, P. Cimiano, A. Frank, and S. Racioppa, "SOBA: SmartWeb Ontologybased Annotation," in Proceedings of the Demo Session at 5th International Semantic Web Conference, Athens, USA, 2006.

[45] N. Kiyavitskaya, N. Zeni, J. R. Cordy, L. Mich, and J. Mylopoulos, "Cerno: Lightweight tool support for semantic annotation of textual documents," Data Knowl. Eng., vol. 68, no. 12, pp. 1470-1492, Dec. 2009.

[46] K. Petridis, D. Anastasopoulos, C. Saathoff, N. Timmermann, Y. Kompatsiaris, and S. Staab, "M-OntoMat-Annotizer: Image Annotation Linking Ontologies and Multimedia Low-Level Features," in Proceedings of the 10th International Conference on Knowledge-Based \& Intelligent Information \& Engineering Systems, Bournemouth, UK, 2006, vol. 4253, pp. 633-640.

[47] A. Chakravarthy, F. Ciravegna, and V. Lanfranchi, "Cross-media Document Annotation and Enrichment," in Proceedings of the 5th International Semantic Web Conference, Athens, Georgia, USA, 2006.

[48] C. Saathoff, S. Schenk, and A. Scherp, "KAT: The K-Space Annotation Tool," in Proceedings of the 3rd International Conference on Semantic And digital Media Technologies, Koblenz, Germany, 2008, pp. 1-2.

[49] D. Turnbull, L. Barrington, D. Torres, and G. Lanckriet, "Semantic annotation and retrieval of music and sound effects," IEEE Trans. Audio, Speech Lang. Process., vol. 16, no. 2, pp. 467-476, 2008.

[50] G. Schreiber, A. Amin, L. Aroyo, M. van Assem, V. de Boer, L. Hardman, M. Hildebrand, B. Omelayenko, J. van Osenbruggen, A. Tordai, J. Wielemaker, and B. Wielinga, "Semantic Annotation and Search of Cultural-heritage Collections: The MultimediaN E-Culture Demonstrator," Web Semant. Sci. Serv. Agents World Wide Web, vol. 6, no. 4, pp. 243-249, 2008.

[51] M. Lienou, H. Maitre, and M. Datcu, "Semantic Annotation of Satellite Images Using Latent Dirichlet Allocation," IEEE Geosci. Remote Sens. Lett., vol. 7, no. 1, pp. 28 32, Jan. 2010.

[52] J. Tang, R. Hong, S. Yan, T.-S. Chua, G.-J. Qi, and R. Jain, "Image Annotation by kNN-Sparse Graph-based Label Propagation Over Noisily Tagged Web Images," ACM Trans. Intell. Syst. Technol., vol. 2, no. 2, p. Article 14, 2011.

[53] S. Agarwal, S. Handschuh, and S. Staab, "Annotation, composition and invocation of semantic web services," Web Semant. Sci. Serv. Agents World Wide Web, vol. 2, no. 1, pp. 31-48, 2004.

[54] D. Martin, M. Paolucci, and M. Wagner, "Bringing Semantic Annotations to Web Services: OWL-S from the SAWSDL Perspective," in Proceedings of the 6th international Semantic Web Conference and the 2nd Asian Semantic Web Conference, Busan, Korea, 2007, vol. 4825, pp. 340-352. 
[55] J. Puttonen, A. Lobov, M. A. C. Soto, and J. L. M. Lastra, "A Semantic Web Servicesbased Approach for Production Systems Control," Adv. Eng. Informatics, vol. 24, no. 3, pp. 285-299, 2010.

[56] M. Cai, W. Y. Zhang, and K. Zhang, "ManuHub: A semantic web system for ontologybased service management in distributed manufacturing environments," IEEE Trans. Syst. Man, Cybern. Part A Syst. Humans, vol. 41, no. 3, pp. 574-582, 2011.

[57] M. Hepp, F. Leymann, J. Domingue, A. Wahler, and D. Fensel, "Semantic Business Process Management: a Vision Towards Using Semantic Web Services for Business Process Management," in Proceedings of the 2005 IEEE International Conference on e-Business Engineering, Beijing, China, 2005, pp. 535-540.

[58] B. Wetzstein, Z. Ma, A. Filipowska, M. Kaczmarek, S. Bhiri, S. Losada, J.-M. LopezCobo, and L. Cicurel, "Semantic Business Process Management: A Lifecycle Based Requirements Analysis," in Proceedings of the Workshop on Semantic Business Process and Product Lifecycle Management (SBPM 2007), vol. 251, Innsbruck, Austria, 2007, pp. 1-11.

[59] M. Born, F. Dörr, and I. Weber, "User-friendly semantic annotation in business process modeling," in Proceedings of the International Workshop on Human Friendly Service Description Discovery and Matchmaking at the 8th International Conference on Web Information Systems Engineering (WISE 2007), Nancy, France, 2007, pp. 260-271.

[60] S. Madnick and H. Zhu, "Improving data quality through effective use of data semantics," Data Knowl. Eng., vol. 59, no. 2, pp. 460-475, Nov. 2006.

[61] D. Dou, P. LePendu, S. Kim, and P. Qi, "Integrating Databases into the Semantic Web through an Ontology-Based Framework," in Proceedings of the 22nd International Conference on Data Engineering Workshops (ICDEW'06), Atlanta, GA, USA, 2006, pp. 54-63.

[62] C. Tao and D. W. Embley, "Automatic hidden-web table interpretation, conceptualization, and semantic annotation," Data Knowl. Eng., vol. 68, no. 7, pp. 683-703, Jul. 2009.

[63] J. Nogueras-Iso, M. Á. Latre, R. Béjar, P. R. Muro-Medrano, and F. J. Zarazaga-Soria, "A model driven approach for the development of metadata editors, applicability to the annotation of geographic information resources," Data Knowl. Eng., vol. 81-82, pp. 118-139, Nov. 2012.

[64] Q. Z. Yang and Y. Zhang, "Semantic Interoperability in Building Design: Methods and Tools," Comput. Des., vol. 38, no. 10, pp. 1099-1112, 2006.

[65] W. Y. Zhang and J. W. Yin, "Exploring Semantic Web Technologies for Ontologybased Modeling in Collaborative Engineering Design," Int. J. Adv. Manuf. Technol., vol. 36, no. 9-10, pp. 833-843, 2008.

[66] O. Hisarciklilar and J.-F. Boujut, "A Speech Act Theory-based information model to support design communication through annotations," Comput. Ind., vol. 60, no. 7, pp. 510-519, Sep. 2009.

[67] L. Papaleo and L. De Floriani, "Semantic-Based Segmentation and Annotation of 3D Models," in Proceedings of the 15th International Conference on Image Analysis and Processing, Solerno, Italy, 2009, vol. 5716 LNCS, pp. 103-112.

[68] D. Völz, A. Schüle, and R. Anderl, "An Approach To Use Semantic Annotations In Global Product Development To Bridge The Gap In Interdisciplinary And Intercultural Communication," in Proceedings of the 4th International Conference on 
Knowledge Generation, Communication and Management, Orlando, Florida, USA, 2010.

[69] J. Zhao, C. Goble, R. Stevens, and S. Bechhofer, "Semantically Linking and Browsing Provenance Logs for E-science," in Proceedings of the 1st International IFIP Conference on Semantics of a Networked World, Paris, France, 2004.

[70] B. Cantalupo, L. Giammarino, N. Matskanis, M. Surridge, and F. Silvestri, "P5.3.1 Semantic Workflow Representation and Samples," Work Package Report of the NextGRID Project, 2005.

[71] H. L. Truong, S. Dustdar, and T. Fahringer, "Performance Metrics and Ontologies for Grid Workflows," Futur. Gener. Comput. Syst., vol. 23, no. 6, pp. 760-772, 2007.

[72] M. P. Guimarães and M. C. Cavalcanti, "Enabling Annotation Provenance in Bioinformatics Workflow Applications," in Proceedings of the 5th Brazilian Symposium on Bioinformatics, Rio de Janeiro, Brazil, 2010.

[73] P. Missier, S. S. Sahoo, J. Zhao, C. Goble, and A. Sheth, "Janus: From workflows to semantic provenance and linked open data," in Proceedings of the 3rd International Provenance and Annotation Workshop, Troy, NY, USA, 2010, vol. 6378 LNCS, pp. 129-141.

[74] D. de Oliveira, E. Ogasawara, J. Dias, F. Baião, and M. Mattoso, "Ontology-based Semi-automatic Workflow Composition,” J. Inf. Data Manag., vol. 3, no. 1, pp. 6172, 2012.

[75] D. R. Ferreira, S. Alves, and L. H. Thom, "Ontology-Based Discovery of Workflow Activity Patterns," in Proceedings of the 2nd International Workshop on Reuse in Business Process Management at the 9th International Conference on Business Process Management, Clermont-Ferrand, France, 2012, vol. 100 LNBIP, pp. 314-325.

[76] F. Lévy, A. Guissé, A. Nazarenko, N. Omrane, and S. Szulman, "An Environment for the Joint Management of Written Policies and Business Rules," in Proceedings of the 22nd IEEE International Conference on Tools with Artificial Intelligence, Arras, France, 2010, vol. 2, pp. 142-149.

[77] A. Nazarenko, A. Guissé, F. Lévy, N. Omrane, and S. Szulman, "Integrating Written Policies in Business Rule Management Systems," in Proceedings of the 5th International Symposium on Rules: Research Based and Industry Focused (RuleML2011-Europe), Barcelona, Spain, 2011, vol. 6826, pp. 99-113.

[78] N. Omrane, A. Nazarenk, P. Rosina, S. Szulman, and C. Westphal, "Lexicalized Ontology for a Business Rules Management Platform: An Automotive Use Case," in Proceedings of the 5th International Symposium on Rules: Research Based and Industry Focused (RuleML2011-America), Florida, USA, 2011, pp. 179-192.

[79] S.-P. Ma, C.-H. Li, C.-Y. Huang, Y.-Y. Fanjiang, and J.-Y. Kuo, "Semantic web service discovery based on business rule annotation," in Proceedings of the 2011 International Conference on Machine Learning and Cybernetics, Guilin, China, 2011, vol. 2, pp. 932-937.

[80] C. de Sainte Marie, M. I. Escudero, and P. Rosina, "The ONTORULE Project: Where Ontology Meets Business Rules.," in Proceedings of the 55th International Conference on Web Reasoning and Rule Systems, Galway, Ireland, 2011, vol. 6902, pp. 24-29.

[81] OMG, "Semantics Of Business Vocabulary And Rules (SBVR)," 2013. [Online]. Available: http://www.omg.org/spec/SBVR/1.2/. 
[82] F. Gailly and G. Geerts, “Ontology-Driven Business Rule Specification,” J. Inf. Syst., vol. 27, no. 1, pp. 79-104, 2013.

[83] D. Gašević and V. Devedžić, "Petri net ontology," Knowledge-Based Syst., vol. 19, no. 4, pp. 220-234, Aug. 2006.

[84] R.-S. Chen and M. Tu, "Development of an agent-based system for manufacturing control and coordination with ontology and RFID technology," Expert Syst. Appl., vol. 36, no. 4, pp. 7581-7593, May 2009.

[85] K.-Y. Seo, G.-K. Park, C.-S. Lee, and M.-H. Wang, "Ontology-based fuzzy support agent for ship steering control," Expert Syst. Appl., vol. 36, no. 1, pp. 755-765, Jan. 2009.

[86] S. Park, H. Ahn, and E. Choi, "Ontology Based Intelligent Monitoring-Control System," in Proceedings of the 2nd International Conference on Advanced Science and Technology, Miyazaki, Japan, 2010.

[87] K. Rahmani and V. Thomson, "Ontology based interface design and control methodology for collaborative product development," Comput. Des., vol. 44, no. 5, pp. 432-444, May 2012.

[88] J. C. Vidal, M. Lama, and A. Bugarín, "Petri net-based engine for adaptive learning," Expert Syst. Appl., vol. 39, no. 17, pp. 12799-12813, Dec. 2012.

[89] C. Choi, J. Choi, and P. Kim, "Ontology-based access control model for security policy reasoning in cloud computing," J. Supercomput., vol. 67, no. 3, pp. 711-722, Jul. 2013.

[90] D. Berardi, D. Calvanese, and G. Degiacomo, "Reasoning on UML class diagrams," Artif. Intell., vol. 168, no. 1-2, pp. 70-118, Oct. 2005.

[91] G. Guizzardi, “Ontological foundations for structural conceptual models," $\mathrm{PhD}$ Thesis, University of Twente, 2005.

[92] F. S. Parreiras and S. Staab, "Using ontologies with UML class-based modeling: The TwoUse approach,” Data Knowl. Eng., vol. 69, no. 11, pp. 1194-1207, Nov. 2010.

[93] Z. Xu, Y. Ni, W. He, L. Lin, and Q. Yan, "Automatic extraction of OWL ontologies from UML class diagrams: a semantics-preserving approach," World Wide Web, vol. 15, no. 5-6, pp. 517-545, Nov. 2011.

[94] E. Yahia, A. Aubry, and H. Panetto, "Formal measures for semantic interoperability assessment in cooperative enterprise information systems," Comput. Ind., vol. 63, no. 5, pp. 443-457, Jun. 2012.

[95] C. M. Keet and P. R. Fillottrani, "Toward an Ontology-Driven Unifying Metamodel for UML Class Diagrams, EER, and ORM2," in Proceedings of the 32nd International Conference on Conceptual Modeling, Hong-Kong, China, 2013.

[96] S. F. Smith and M. A. Becker, "An Ontology for Constructing Scheduling Systems," 1997.

[97] R. Basra, K. Lü, G. Rzevski, and P. Skobelev, "Resolving Scheduling Issues of the London Underground Using a Multi-agent System," in Proceedings of the 2nd International Conference on Industrial Applications of Holonic and Multi-Agent Systems (HoloMAS '05), Copenhagen, Denmark, 2005.

[98] J. Himoff, G. Rzevski, and P. Skobelev, "Magenta technology multi-agent logistics iScheduler for road transportation," in Proceedings of the 5th international joint conference on Autonomous agents and multiagent systems (AAMAS '06), New York, New York, USA, 2006, pp. 1514 - 1521. 
[99] G. Rzevski, J. Himoff, and P. Skobelev, "Magenta Technology: A Family of MultiAgent Intelligent Schedulers," in Proceedings of the 1st international workshop on Software Agents in Information Systems and Industrial Applications (SAISIA), Karlsruhe, Germany, 2006.

[100] C.-S. Lee, C.-C. Jiang, and T.-C. Hsieh, "A genetic fuzzy agent using ontology model for meeting scheduling system," Inf. Sci. (Ny)., vol. 176, no. 9, pp. 1131-1155, May 2006.

[101] S. Andreev, G. Rzevski, P. Shviekin, P. Skobelev, and I. Yankov, "A Multi-agent Scheduler for Rent-a-Car Companies," in Proceedings of the 4th International Conference on Industrial Applications of Holonic and Multi-Agent Systems (HoloMAS '09), Linz, Austria, 2009.

[102] G. Polhill, N. Gotts, N. Sánchez-Maroño, E. Pignotti, Ó. Fontenla-Romero, M. Rodríguez-García, A. Alonso-Betanzos, P. Edwards, and T. Craig, "An ontologybased design for modeling case studies of everyday proenvironmental behaviour in the workplace," in Proceedings of the 6th biannial meeting of the International Environmental Modelling and Software Society, Leipzig, Germany, 2012.

[103] K. . Masuwa-Morgan and P. Burrell, "Justification of the need for an ontology for accessibility requirements (Theoretic framework)," Interact. Comput., vol. 16, no. 3, pp. 523-555, Jun. 2004.

[104] R. Roy, C. I. V. Kerr, P. J. Sackett, and J. Corbett, "Design Requirements Management using an Ontological Framework," CIRP Ann. - Manuf. Technol., vol. 54, no. 1, pp. 109-112, Jan. 2005.

[105] D. E. Herlea Damian, C. M. Jonker, J. Treur, and N. J. E. Wijngaards, "Integration of behavioural requirements specification within compositional knowledge engineering," Knowledge-Based Syst., vol. 18, no. 7, pp. 353-365, Nov. 2005.

[106] K. Sandkuhl and A. Billig, "Towards ontology-based requirements management in automotive electronics," in Proceedings of the 12th World Congress of the International Federation of Automatic Control (IFAC '06), Saint-Etienne, France, 2006, pp. 677-682.

[107] G. Cai, "Requirement Driven Service Composition: An Ontology-Based Approach," in Proceedings of the 6th IFIP TC 12 International Conference (IIP 2010), Manchester, UK, 2010, pp. 16-25.

[108] A. L. Szejka, A. Aubry, H. Panetto, O. Canciglieri Junior, and E. R. Loures, "Towards a conceptual framework for requirements interoperability in complex systems engineering," in Proceedings of the 9th International Workshop on Enterprise Integration, Interoperability and Networking (EI2N'14) at the OnTheMove Federated Conferences, Amantea, Calabria, Italy, 2014. 


\section{Biography}

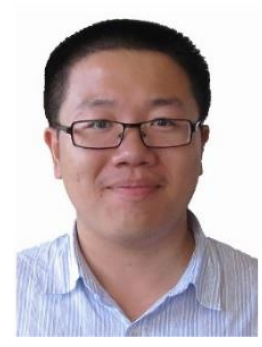

Yongxin Liao is the corresponding author. He is a Post-Doc researcher at the Graduate Program in Production Engineering and Systems (PPGEPS), Pontifical Catholic University of Paraná (PUCPR), Curitiba, Brazil. He obtained his $\mathrm{PhD}$ degree in Automatic from the University of Lorraine in 2013. He obtained his Bachelor degree in Software Engineering from the Harbin Institute of Technology in 2008, and his Master degrees in Enterprise Computing and Engineering \& Software Engineering from the University of Bordeaux $1 \&$ the Harbin Institute of Technology in 2010. He specializes in production engineering, Semantic Web, data structuring, algorithm design, and programming.

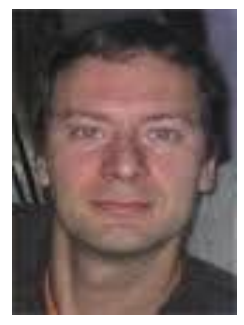

Mario Lezoche is an assistant professor at the University of Lorraine, where he teaches object-oriented software engineering and database development. $\mathrm{He}$ conducts his research on Enterprise Model Interoperability at the Research Centre for Automatic Control (CRAN), Joint Research Unit with CNRS. He graduated at the Roma TRE University in Computer Science Engineering. He received his $\mathrm{PhD}$ degree in Computer Science Engineering in 2009. He has good experience in Semantic Web research and in models and semantics for systems interoperability. He is presently working on a conceptualization approach for enterprise information systems interoperability.

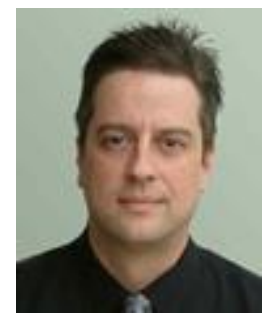

Eduardo Rocha Loures is an assistant professor at the Graduate Program in Production Engineering and Systems (PPGEPS), Pontifical Catholic University of Paraná (PUCPR), Curitiba, Brazil. He received his Bachelor degree in Electrical Engineering from the Federal Technological University of Paraná, his Master degree in Informatics from the Pontifical Catholic University of Paraná, and his $\mathrm{PhD}$ in Industrial Systems from the University of Toulouse. He was a Post-Doc researcher at the Research Centre for Automatic Control (CRAN). His research interests include automated manufacturing systems, business process management, process aware information systems, and enterprise interoperability assessment. 


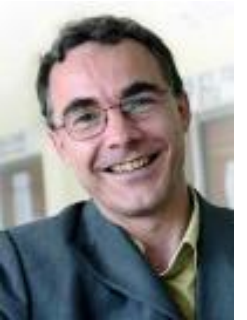

Hervé Panetto is a full Professor of Enterprise Information Systems at the University of Lorraine where he teaches Information Systems modeling and development at the School of Engineering in Information Technology and conducts research at the CRAN. His is working on information systems modeling for enterprise applications and processes interoperability, with applications in enterprise modeling, manufacturing processes modeling and furniture data modeling. He is author or co-author of more than 80 papers in the field of automation engineering, enterprise modeling and enterprise systems integration and interoperability. He is currently Chair of the IFAC Technical Committee 5.3 "Enterprise Integration and Networking".

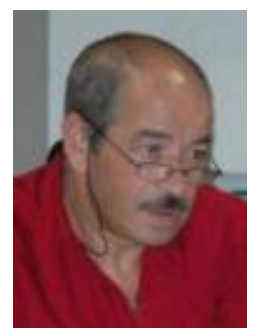

Nacer Boudjlida is a full Professor at the University of Lorraine and a researcher at the Lorraine Research Laboratory in Computer Science and its Applications (LORIA), Joint Research Unit with CNRS. As a professor, his lectures include the various facets of databases (DBMS, database design, distribution, architecture, administration and so on). As a researcher, his domain of interest includes process modeling and support, distributed and cooperative computing, semantic-based mediated architectures. He authored two books on databases and numerous papers on software systems integration and interoperability, on software process modeling and support. 